\title{
Globe Positioning in the Orbit among Filipinos Scanned at the Philippine General Hospital from November 2009 to February 2010
}

\author{
Nonette A. Cupino, ${ }^{1}$ Erwin John T. Carpio ${ }^{1}$ and Paulo Maria N. Pagkatipunan ${ }^{2}$ \\ ${ }^{1}$ Department of Radiology, College of Medicine and Philippine General Hospital, University of the Philippines Manila \\ ${ }^{2}$ Department of Ophthalmology, College of Medicine and Philippine General Hospital, University of the Philippines Manila
}

\begin{abstract}
Objective. To determine normal Filipino values of globe positioning in the orbit using Computed Tomography.

Methods. 58 individuals were divided into age groups below 20 and 20 and above. CT images with constant settings were obtained. The distance between the lateral orbital rims $(A)$, the shortest distance between line $A$ and the corneal center (B), medial and lateral orbital rims $(C)$, and the distance between line $C$ and the corneal apex crossing the center of the lens (D) were measured, and the $\mathrm{B} / \mathrm{A}$ and $\mathrm{D} / \mathrm{C}$ ratios calculated. The mean, median, and range in millimeters were grouped in terms of age, sex, and laterality.
\end{abstract}

Results. Between the age groups, there was a significant difference in the average values of $A, B$, and $C$, but not the $B / A$ and $D / C$ ratios. Gender comparison for group 2 showed statistical difference in the average values of $B$ and $C$, but not the $A, D, B / A$ and $D / C$ ratios. All the parameters in both groups showed no significant difference when the right and left eyes were compared.

Conclusion. Age group comparison showed statistically significant difference in the average values of $A, B$, and $C$ which may be attributable to growth changes. Gender comparison in group 2 showed significant difference in B and C. Males had a greater degree of protrusion than females. The right and left eye showed no significant difference in any of the measured parameters. Throughout the study, both $B / A$ and $D / C$ ratios showed no significant difference among gender and age suggesting that such ratios may be used as an index for setting normal globe positioning in the orbit.

Key Words: age, computed tomography, globe, orbit, position

\footnotetext{
Corresponding author: Nonette A. Cupino,MD

Department of Radiology

Philippine General Hospital

University of the Philippines Manila

Taft Avenue, Ermita, Manila 1000 Philippines

Telephone: +6325548471

Fax No: +632 5226597

Email: nacmd@yahoo.com
}

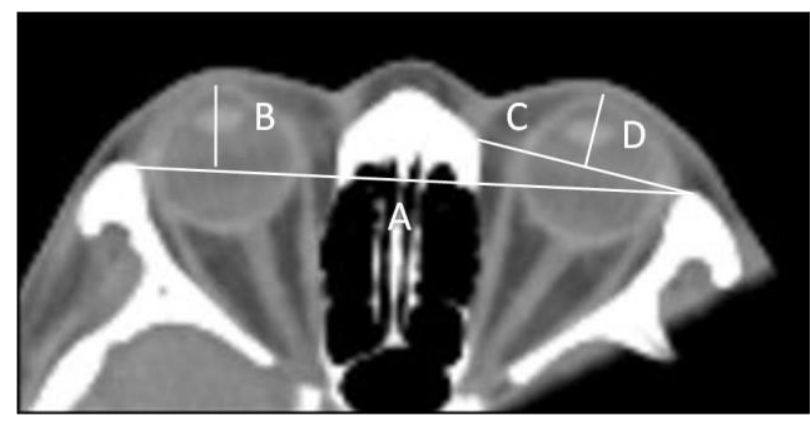

Figure 1. Measurements taken by CT.

\section{Introduction}

Normal values for the skull on plain radiographs have long been in practical use for the evaluation and discernment of disease. However, with the advent of multidetector computed tomography (MDCT), these values may no longer be accurate enough to complement the increased sensitivity of the modern imaging modality. A number of studies have already been conducted to reassess such values using multidetector CT. Furthermore, with the axial, coronal, and sagittal views available, the propensity towards a more exacting plethora of measurements will undoubtedly be a mainstay for future radiologic studies.

One of the best studies for these have generally focused on the more obvious advantages of computed tomography in the evaluation of soft tissue densities in the brain to assess infarcts, areas of ischemia, and other morphologic insults. ${ }^{1,2,3,4}$ In terms of the orbit, only a limited number of CT studies have focused on delineating the normal or standard measurements. Further still, only a handful of these have described an Asian population. ${ }^{5}$ The importance of such measurements cannot be emphasized enough. Changes in position, density, shape, and size in orbital structures such as the extraocular muscles, nerve sheath, and globe can all be significant markers in the evaluation of orbital disease. A number of investigators have already tackled these known issues, particularly in the evaluation of exophthalmos for a Korean population.5,6 Given the racial variables governing osseous orbital configurations and genetic predispositions affecting the morphology of the globe, it would therefore be prudent to conduct a similar study to ascertain orbital measurements for the Philippine 
setting. Such data may not only be more applicable locally but may also add to the increasing volume of data which can be used to represent a more general Asian population.

With the dearth in data regarding normal globe positioning even with the advent of computed tomography, only physical examination tells the clinician if the globe is positioned normally or abnormally. Thus, the ophthalmologists and orbit specialists rely on Hertel's exophthalmometer, a device that has long been used for the clinical evaluation of globe positioning. However, it has been criticized for its lack of accuracy and reproducibility, as well as its dependence on many factors. These factors include positioning of the foot plate, the state of the underlying tissue (with or without inflammation) as well as the amount of compression produced by the clinician. When compared with this method of evaluation, CT values have already shown a significant difference in the aforementioned Korean study. ${ }^{6}$ Nevertheless, such a comparison may also be made with a Filipino population.

There are more and more instances in which ophthalmologists must decide whether a particular patient has globes positioned normally in the orbit, such as in cases of thyroid orbitopathy, orbital pseudotumor, lacrimal gland tumors or any pathologies involving the orbit. The purpose of this study is to ascertain Filipino orbital values via MDCT for a better and more precise normal positioning of the globe within the orbit using methods already described in previous studies.5,6 This, hopefully, will further aid in the compatibility of data for future comparison and synchronization.

\section{Methods}

The methods that follow are taken partly and selectively from the extensive work illustrated in two studies by Kim IT et al. ${ }^{6}$ and Lee JS et al. ${ }^{5}$

Population/Subjects: 58 individuals (a total of 116 eyes) scanned at the PGH CT Scan Suite from November 2009 to February 2010 were selected. They were divided into two groups. Those with ages below 20 were classified as group 1 while those 20 years old and above were classified as group 2. Exclusion criteria included orbital wall fractures or deformities, orbital neoplasms/inflammations, and the presence of orbital implants that may confound the data.

Image Acquisition: Images were obtained using either a 2slice or 16-slice CT scanner (Somatom Siemens). The selected image for measurements should include the center of the lens, corneal apex, the largest eyeball contour, the optic canal $^{7}$ and optic nerve on the axial view of the orbit on CT. Scanned images were performed at a constant window level of 50 Hounsfield Units (HU) and window width of $450 \mathrm{HU}$. Cuts at least $3 \mathrm{~mm}$ will be used.
Measurements: Six parameters were measured as follows:

1. Line A: The distance between the lateral orbital rims of both eyes ${ }^{6}$ otherwise known as the "interzygomatic line" which depicts the transversal head size and is defined by the anterior extent of the lateral bony orbital rims. ${ }^{5}$

2. Line B: The shortest distance between Line $\mathbf{A}$ and the corneal center. ${ }^{6}$

3. Line $\mathbf{C}$ : The distance between the medial and lateral orbital rims. The medial orbital rim is the point where the anterior process of the maxilla, frontal bone, and uppermost part of the posterior lacrimal crest intersect. ${ }^{6}$

4. Line D: The length of the line beginning at the corneal apex, passing through the center of the lens and ending at its intersection with Line C. ${ }^{6}$

5. The $\mathbf{B} / \mathbf{A}$ ratio. ${ }^{6}$

6. The $\mathbf{D} / \mathbf{C}$ ratio. Stipulated to have a persistent value of 0.3 or 0.31 regardless of age, sex, or laterality. ${ }^{6}$

An independent-samples T-test ${ }^{5}$ or student's T-test ${ }^{6}$ was used to compare data with a statistical significance at the 0.05 p-level.(Appendix A)

\section{Results}

Group 1 ( $<20$ years old) and Group 2 ( $\geq 20$ years old) were compared. In group 1, the mean value was $88.84 \mathrm{~mm}$ (range: $76.90-101.00 \mathrm{~mm}$, median: $87.55 \mathrm{~mm}$ ) for the distance between both lateral orbital rims (A), $14.19 \mathrm{~mm}$ (range: 11.20-16.60 mm, median: $14.40 \mathrm{~mm}$ ) for the shortest distance between the corneal apex and the line A (B), $35.07 \mathrm{~mm}$ (range: $30.20-42.70 \mathrm{~mm}$, median: $34.90 \mathrm{~mm}$ ) for the distance between the lateral and medial orbital rim (C), 10.08 (range: 7.0-12.6 mm, median: $10.10 \mathrm{~mm}$ ) for the length of the line passing through the lens center from the corneal apex to the line $C(D), 0.16$ for the $\mathbf{B} / \mathbf{A}$ ratio and 0.29 for the $\mathbf{D} / \mathbf{C}$ ratio. (Table 1)

In group 2, the mean value was $97.58 \mathrm{~mm}$ (range: $89.20-$ $109.40 \mathrm{~mm}$, median: $97.75 \mathrm{~mm}$ ) for the distance between both lateral orbital rims (A), $15.10 \mathrm{~mm}$ (range: 10.10-22.50 $\mathrm{mm}$, median: $14.70 \mathrm{~mm}$ ) for the shortest distance between the corneal apex and the line A (B), $37.90 \mathrm{~mm}$ (range: 33.60$43.50 \mathrm{~mm}$, median: $37.60 \mathrm{~mm}$ ) for the distance between the lateral and medial orbital rim (C), 10.90 (range: 6.8-16.1 mm, median: $10.45 \mathrm{~mm}$ ) for the length of the line passing through the lens center from the corneal apex to the line C (D), 0.15 for the $\mathbf{B} / \mathbf{A}$ ratio and 0.29 for the $\mathbf{D} / \mathbf{C}$ ratio.

There was no statistically significant difference between the two age groups for parameters B/A $(p=0.19888793)$ and $\mathbf{D} / \mathbf{C}(0.942841961)$. However, there was a significant difference between the average values of $\mathbf{A}$ $\left(\mathrm{p}=4.83751 \times 10^{-7}\right), \mathbf{B}(\mathrm{p}=0.016000213)$ and $\mathbf{C}\left(\mathrm{p}=3.16563 \times 10^{-7}\right)$. 
Table 1. Measured values by age group.

\begin{tabular}{rrrr}
\hline 2 age groups & GROUP 1 <20 & GROUP 2 $\geq \mathbf{2 0}$ & P \\
\hline PATIENTS & 14 & 44 & \\
A AVERAGE in mm & $88.84 \pm 6.05$ & $97.58 \pm 4.64$ & $4.83751 \times 10^{-7}$ \\
RANGE & $76.90-101.00$ & $89.20-109.40$ & \\
MEDIAN & 87.55 & 97.75 & \\
RANGE & $11.20-16.60$ & $10.10-22.50$ & \\
BEDIAN & 14.4 & 14.7 & \\
RANERAGE in mm & $35.07 \pm 2.97$ & $37.9 \pm 2.20$ & $3.16563 \times 10^{-7}$ \\
MEDIAN & $30.20-42.70$ & $33.60-43.50$ & \\
C AVERAGE in mm & 34.9 & 37.6 & \\
RANGE & $10.08 \pm 1.40$ & $10.9 \pm 2.39$ & 0.026684508 \\
MEDIAN & $7.0-12.60$ & $6.80-16.10$ & \\
D AVERAGE in mm & 10.1 & 10.45 & \\
B/A RATIO & $0.16 \pm 0.02$ & $0.15 \pm 0.03$ & 0.19888793 \\
D/C RATIO & $0.29 \pm 0.04$ & $0.29 \pm 0.06$ & 0.942841961 \\
\hline
\end{tabular}

Gender comparison in group 1 was not done since there was significant inequality in the male to female distribution.

In group 2 female and male groups were compared. The results were as follows. The mean value of $\mathbf{A}$ was $98.97 \mathrm{~mm}$ (range: 89.90-109.40 mm, median: $98.60 \mathrm{~mm}$ ) for males and $96.42 \mathrm{~mm}$ (range: $89.20-102.00 \mathrm{~mm}$, median: $97.40 \mathrm{~mm}$ ) for females. The mean value of $\mathbf{B}$ was $15.83 \mathrm{~mm}$ (range: 11.00$22.50 \mathrm{~mm}$, median: $15.15 \mathrm{~mm}$ ) for males and $14.50 \mathrm{~mm}$ (range: 10.10-20.20 mm, median: $14.10 \mathrm{~mm}$ ) for females. The mean value of $\mathrm{C}$ was $38.53 \mathrm{~mm}$ (range: $34.70-43.50 \mathrm{~mm}$, median: $38.05 \mathrm{~mm}$ ) for males and $37.38 \mathrm{~mm}$ (range: $33.60-$ $41.60 \mathrm{~mm}$, median: $37.30 \mathrm{~mm}$ ) for females. The mean value of $\mathbf{D}$ was $11.11 \mathrm{~mm}$ (range: $7.00-16.10 \mathrm{~mm}$, median: 10.50 $\mathrm{mm}$ ) for males and $10.73 \mathrm{~mm}$ (range: 6.80-16.10 mm, median: $10.40 \mathrm{~mm}$ ) for females. The mean $\mathbf{B} / \mathbf{A}$ ratio was 0.16 for males and 0.15 for females. The $\mathrm{D} / \mathrm{C}$ ratio was approximately 0.29 for both males and females. (Table 2) (Appendix B)

There was no significant statistical difference between both genders for the averages of $\mathbf{A}(p=0.068920916)$ and $\mathbf{D}$ $(p=0.45915119)$ as well as the $\mathbf{B} / \mathbf{A}$ ratio $(p=0.074715905)$ and $\mathrm{D} / \mathrm{C}$ ratio $(\mathrm{p}=0.974098054)$ (Appendix $\mathrm{B})$. There was a statistical difference between the average values of $\mathbf{B}$ $(\mathrm{p}=0.014694107)$ and $\mathrm{C}(\mathrm{p}=0.013394469)$.

Comparing the right with the left eye in group 1, the results were as follows. The mean value was $88.84 \mathrm{~mm}$ (range: 76.90-101.00 mm, median: $87.55 \mathrm{~mm}$ ) for $\mathbf{A}, 14.31$ mm (range: 11.7-16.6 mm, median: $14.4 \mathrm{~mm}$ ) for $\mathbf{B}$ of the right eye, $14.06 \mathrm{~mm}$ (ranges: $11.20-15.90 \mathrm{~mm}$, median: 14.40 $\mathrm{mm}$ ) for $\mathbf{B}$ of the left eye. The mean value of $\mathbf{C}$ was $34.61 \mathrm{~mm}$ (range: $30.20-42.70 \mathrm{~mm}$, median: $34.90 \mathrm{~mm}$ ) for the right eye and $35.53 \mathrm{~mm}$ (range: $30.80-42.30 \mathrm{~mm}$, median: $34.90 \mathrm{~mm}$ ) for the left eye. The mean value of $\mathbf{D}$ was $10.04 \mathrm{~mm}$ (range: 7.00-12.6 mm, median: $9.8 \mathrm{~mm}$ ) for the right eye, $10.11 \mathrm{~mm}$ (range: $8.10-12.10 \mathrm{~mm}$, median: $10.20 \mathrm{~mm}$ ) for the left eye. The B/A and D/C ratios were 0.16 and 0.29 for both eyes, respectively.(Appendix B) There was no statistically significant difference in all parameters between the right and left eyes. (Table 3)
Table 2. Group 2: Female vs. male

\begin{tabular}{rccc}
\hline$\geq \mathbf{2 0}$ & FEMALE & MALE & P \\
\hline PATIENTS & 24 & 20 & \\
A AVERAGE in mm & $96.42 \pm 3.78$ & $98.97 \pm 5.26$ & 0.068920916 \\
RANGE & $89.20-102.00$ & $89.90-109.40$ & \\
MEDIAN & 97.4 & 98.6 & \\
B AVERAGE in mm & $14.5 \pm 2.46$ & $15.83 \pm 2.54$ & 0.014694107 \\
RANGE & $10.10-20.20$ & $11.00-22.50$ & \\
MEDIAN & 14.1 & 15.15 & \\
C AVERAGE in mm & $37.38 \pm 1.97$ & $38.53 \pm 2.32$ & 0.013394469 \\
RANGE & $33.60-41.60$ & $34.70-43.50$ & \\
MEDIAN & 37.3 & 38.05 & \\
D AVERAGE in mm & $10.73 \pm 2.41$ & $11.11 \pm 2.37$ & 0.45915119 \\
RANGE & $6.80-16.10$ & $7.00-16.10$ & \\
MEDIAN & 10.4 & 10.5 & \\
B/A RATIO & $0.15 \pm 0.02$ & $0.16 \pm 0.03$ & 0.074715905 \\
D/C RATIO & $0.29 \pm 0.07$ & $0.29 \pm 0.06$ & 0.974098054 \\
\hline
\end{tabular}

Table 3. Group 1: Right and left eyes

\begin{tabular}{rccc}
\hline$<$ 20 & RIGHT & LEFT & P \\
\hline PATIENTS & 14 & 14 & \\
A AVERAGE in mm & \multicolumn{2}{c}{$88.84 \pm 6.05$} & \\
RANGE & \multicolumn{2}{c}{$76.90-101.00$} & \\
MEDIAN & \multicolumn{2}{c}{87.55} & \\
RANGE & $11.70-16.60$ & $11.20-15.90$ & \\
B AVERAGE in mm & 14.4 & 14.4 & \\
MEDIAN & $34.61 \pm 3.18$ & $35.53 \pm 2.78$ & 0.424842567 \\
RANGE & $30.20-42.70$ & $30.80-42.30$ & \\
MEDIAN & 34.9 & 34.9 & \\
C AVERAGE in mm & $10.04 \pm 1.67$ & $10.11 \pm 1.12$ & 0.905667123 \\
RANGE & $7.00-12.60$ & $8.10-12.10$ & \\
MEDIAN & 9.8 & 10.2 & \\
D AVERAGE in mm & $0.16 \pm 0.02$ & $0.16 \pm 0.01$ & 0.609826774 \\
B/A RATIO & $0.29 \pm 0.04$ & $0.29 \pm 0.03$ & 0.720616769 \\
\hline
\end{tabular}

In group 2, the mean value of each parameter in the right and left eye were as follows. The mean value was 97.58 mm (range: $89.20-109.40 \mathrm{~mm}$, median: $97.75 \mathrm{~mm}$ ) for $\mathbf{A}$. The mean value for $\mathbf{B}$ was $15.23 \mathrm{~mm}$ (range: 10.50-22.50 mm, median: $14.80 \mathrm{~mm}$ ) for the right eye and $14.98 \mathrm{~mm}$ (range: 10.10-21.00 mm, median: $14.35 \mathrm{~mm}$ ) for the left eye. The mean value for C was $37.93 \mathrm{~mm}$ (range: $33.60-43.10 \mathrm{~mm}$, median: $37.65 \mathrm{~mm}$ ) for the right eye and $37.88 \mathrm{~mm}$ (range: 34.20-43.50 mm, median: $37.55 \mathrm{~mm}$ ) for the left eye. The mean value of $\mathbf{D}$ was $10.99 \mathrm{~mm}$ (range: 6.80-11.61 mm, median: $10.70 \mathrm{~mm}$ ) for the right eye and $10.81 \mathrm{~mm}$ (range: 7.0-16.10 mm, median: $10.40 \mathrm{~mm}$ ) for the left eye. (Table 4)

The $\mathbf{B} / \mathbf{A}$ ratio was 0.16 for the right eye and 0.15 for the left with no statistically significant difference $(p=0.641276306)$. Similarly, there was no significant difference $(\mathrm{p}=0.772359222)$ between the $\mathrm{D} / \mathrm{C}$ ratio of the right eye (0.29) and that of the left (0.29). (Appendix B) There was no significant difference between the left and the right eye for the rest of the parameters. 
Table 4. Group 2: Right and left eye

\begin{tabular}{rccc}
\hline$\geq 20$ & RIGHT & LEFT & P \\
\hline PATIENTS $\geq 20$ & 44 & 44 & \\
YEARS OLD & \multicolumn{4}{c}{$97.58 \pm 4.64$} \\
A AVERAGE in mm & \multicolumn{2}{c}{$89.20-109.40$} \\
RANGE & \multicolumn{2}{c}{97.75} \\
MEDIAN & $15.23 \pm 2.59$ & $14.98 \pm 2.57$ & 0.650528745 \\
B AVERAGE in mm & $10.10-21.00$ & \\
RANGE & $10.50-22.50$ & 14.35 & \\
MEDIAN & 14.8 & $37.88 \pm 2.31$ & 0.919583625 \\
C AVERAGE in mm & $37.93 \pm 2.10$ & $34.20-43.50$ & \\
RANGE & $33.60-43.10$ & 37.55 & \\
MEDIAN & 37.65 & $10.81 \pm 2.45$ & 0.723008638 \\
RANGE & $6.80-16.10$ & $7.00-16.10$ & \\
MEDIAN & 10.7 & 10.4 & \\
D AVERAGE in mm & $0.16 \pm 0.03$ & $0.15 \pm 0.03$ & 0.641276306 \\
B/A RATIO & $0.29 \pm 0.06$ & $0.29 \pm 0.07$ & 0.772359222 \\
D/C RATIO & & &
\end{tabular}

In group 2, the mean values of each parameter in the right and left eye of males or females were as follows. The mean value was $98.97 \mathrm{~mm}$ (range: 89.90-109.40 mm, median: $98.60 \mathrm{~mm}$ ) for $\mathbf{A}$ in males and $96.42 \mathrm{~mm}$ (range: 89.20-102.00 mm, median: $97.40 \mathrm{~mm}$ ) for $\mathbf{A}$ in females. The mean value of $\mathbf{B}$ in males was $15.87 \mathrm{~mm}$ (range: $12.40-22.50 \mathrm{~mm}$, median: $15.15 \mathrm{~mm}$ ) for the right eye and $15.79 \mathrm{~mm}$ (range: 11.0-21.00 $\mathrm{mm}$, median: $15.15 \mathrm{~mm}$ ) for the left eye. The mean value of $\mathbf{B}$ in females was $14.70 \mathrm{~mm}$ (range: $10.50-20.20 \mathrm{~mm}$, median: $14.35 \mathrm{~mm}$ ) for the right eye and $14.30 \mathrm{~mm}$ (range: 10.10-19.30 $\mathrm{mm}$, median: $13.90 \mathrm{~mm}$ ) for the left eye. The mean value of $\mathbf{C}$ in males was $38.55 \mathrm{~mm}$ (range: $34.70-43.10 \mathrm{~mm}$, median: $37.90 \mathrm{~mm}$ ) for right eye and $38.52 \mathrm{~mm}$ (range: 34.70-43.50 $\mathrm{mm}$, median: $38.45 \mathrm{~mm}$ ) for the left eye. The mean value of $\mathbf{C}$ in females was $37.40 \mathrm{~mm}$ (range: $33.60-41.00 \mathrm{~mm}$, median: $37.15 \mathrm{~mm}$ ) for the right eye and $37.35 \mathrm{~mm}$ (range: $34.20-41.60$ mm, median: $37.45 \mathrm{~mm}$ ) for the left eye. The mean value of D in males was $11.02 \mathrm{~mm}$ (range: $7.20-14.60 \mathrm{~mm}$, median: $10.70 \mathrm{~mm}$ ) for the right eye and $11.20 \mathrm{~mm}$ (range: $7.00-16.10$ mm, median: $10.10 \mathrm{~mm}$ ) for the left eye. The mean value of D in females was $10.97 \mathrm{~mm}$ (range: $6.80-16.10 \mathrm{~mm}$, median: $10.70 \mathrm{~mm}$ ) for the right eye and $10.49 \mathrm{~mm}$ (range: 7.20-15.40 mm, median: $10.40 \mathrm{~mm}$ ) for the left eye. The $\mathbf{B} / \mathbf{A}$ ratio was 0.15 for females and 0.16 for males. The $\mathbf{D} / \mathbf{C}$ ratio was 0.29 and 0.28 for the right and left eyes of females and 0.28 and 0.29 for the eyes of males, respectively. (Table 5)(Appendix B)

\section{Discussion}

This study used a similar approach to the procedure of Kim and $\mathrm{Choi}^{6}$ using images that included the corneal apex, the center of the lens, the largest eyeball contour, and the optic canal. Through the workstation, multiplanar reconstruction to view an angled plane including as much of the optic nerve as possible was utilized. The HU level and width were set at 50 and 450, respectively. This windowing showed the best balance between the osseous and intraorbital soft tissues. The distance between the lateral orbital rims (A), the shortest distance between line $\mathbf{A}$ and the corneal center (B), medial and lateral orbital rims $(\mathbf{C})$, and the distance between the line $\mathrm{C}$ and the corneal apex crossing the center of the lens (D) were measured. ${ }^{6}$

Table 5. Right and left, female and male

\begin{tabular}{|c|c|c|c|c|}
\hline & \multicolumn{2}{|c|}{ FEMALE } & \multicolumn{2}{|c|}{ MALE } \\
\hline $\begin{array}{l}\text { PATIENTS } \geq 20 \\
\text { YEARS OLD }\end{array}$ & \multicolumn{2}{|c|}{24} & \multicolumn{2}{|c|}{20} \\
\hline A AVERAGE in mm & \multirow{2}{*}{\multicolumn{2}{|c|}{$\begin{array}{c}96.42 \pm 3.78 \\
89.20-102.00\end{array}$}} & \multicolumn{2}{|c|}{$98.97 \pm 5.26$} \\
\hline RANGE & & & 89.90 & 09.40 \\
\hline \multirow[t]{2}{*}{ MEDIAN } & \multicolumn{2}{|c|}{97.4} & \multicolumn{2}{|c|}{98.6} \\
\hline & RIGHT & LEFT & RIGHT & LEFT \\
\hline B AVERAGE in mm & $14.70 \pm 2.60$ & $14.30 \pm 2.35$ & $15.87 \pm 2.50$ & $15.80 \pm 2.64$ \\
\hline RANGE & $10.50-20.20$ & $10.10-19.30$ & $12.40-22.50$ & $11.00-21.00$ \\
\hline MEDIAN & 14.35 & 13.9 & 15.15 & 15.15 \\
\hline C AVERAGE in mm & $37.41 \pm 1.90$ & $37.35 \pm 2.07$ & $38.55 \pm 2.21$ & $38.52 \pm 2.48$ \\
\hline RANGE & $33.60-41.00$ & $34.20-41.60$ & $34.70-43.10$ & $34.70-43.50$ \\
\hline MEDIAN & 37.15 & 37.45 & 37.9 & 38.45 \\
\hline D AVERAGE in $\mathrm{mm}$ & $10.97 \pm 2.52$ & $10.49 \pm 2.33$ & $11.02 \pm 2.18$ & $11.20 \pm 2.60$ \\
\hline RANGE & $6.80-16.10$ & $7.20-15.40$ & $7.20-14.60$ & $7.00-16.10$ \\
\hline MEDIAN & 10.7 & 10.4 & 10.7 & 10.1 \\
\hline B/A RATIO & $0.15 \pm 0.03$ & $0.15 \pm 0.02$ & $0.16 \pm 0.03$ & $0.16 \pm 0.03$ \\
\hline D/C RATIO & $0.29 \pm 0.07$ & $0.28 \pm 0.07$ & $0.29 \pm 0.06$ & $0.29 \pm 0.07$ \\
\hline
\end{tabular}

Between the two age groups (Table 1 ), the average value for A was (88.84 $\mathrm{mm})$ for Group 1 and $(97.58 \mathrm{~mm})$ for group 2. These showed a statistically significant difference $\left(\mathrm{p}=4.83751 \times 10^{-7}\right)$. Similarly, the mean protrusion $(\mathbf{B})$ was $(14.19 \mathrm{~mm})$ for group 1 and $(15.1 \mathrm{~mm})$ for group 2 . These also showed a significant difference $(p=0.016000213)$. These differences have all been previously attributed to the growth and associated changes of the facial bones including the orbital rims and to the simultaneous growth and development of the intraorbital contents. ${ }^{8}$ In general, it is surmised that the lateral orbital rims grow posteriorly with associated anterior protrusion of the globe. The protrusion is further accentuated by the enlargement of the intraorbital contents. ${ }^{6}$ Despite the changes in the face and orbits, there was no significant difference in the $\mathbf{B} / \mathbf{A}$ ratio $(p=0.19888793)$.

There was also a significant difference $\left(p=3.16563 \times 10^{-7}\right)$ among the two age groups for the average values for the distance between the medial and lateral orbital rims $(\mathbf{C})$. The mean values for $(\mathbf{C})$ were $35.07 \mathrm{~mm}$ and $37.9 \mathrm{~mm}$ for groups 1 and 2, respectively. This too has been explained as likely due to the anterior growth of the nasal and anterior process of the maxillary bones while the lateral orbital rims move posteriorly. Regardless, there was no significant difference between the $D / C$ ratios $(p=0.942841961)$ for both groups which had mean value of 0.29 . (Appendix B)

When comparing males and females in Group 2 (Table 2), there was no statistically significant difference in the means of the distance between the lateral orbital rims (A). However, there was a significant difference between the degree of protrusion (B) and in the average distance between the medial and lateral orbital rims $(\mathbf{C})$ with $\mathrm{P}$ values of 0.014694107 and 0.013394469 , respectively. The value of (B) 
showed that males had a greater degree of protrusion than females. The mean protrusion (B) for males and females was $15.83 \mathrm{~mm}$ and $14.5 \mathrm{~mm}$, respectively. Unlike in Choi and Kim's paper, however, there was no significant difference in the $\mathbf{B} / \mathbf{A}$ ratio $(\mathrm{p}=0.074715905)$.

When comparing the right and left eye, there was generally no significant difference in any of the measured parameters.

Throughout the study, both $\mathbf{B} / \mathbf{A}$ and $\mathbf{D} / \mathbf{C}$ ratios showed no significant difference amongst gender and age ranging from 0.15 to 0.16 and 0.28 to 0.29 , respectively.(Appendix B) These are suggestive that such ratios may be used as an index for exophthalmos. The study also supports the initial work of Kim and Choi to show the utility of the D/C ratio as an index for exophthalmos. In the present study however, the mean $\mathrm{D} / \mathrm{C}$ values were slightly lower. The values in the paper by Kim and Choi were 0.30 for their younger age group and 0.31 for their older age group $(\geq 20)$. One reason for this could be the slight differences among patients in the orientation of the eye ball during scanning. Some of the eyes were directed slightly inferiorly while others were directed slightly superiorly. Since the protocol requires the scan plane to include the center of the lens and corneal apex, these differences can operatively decrease the protrusion values (B) and D values. When eyes are closed during scanning, the lack of a point of fixation for the eyes may attribute to this variability. Furthermore, although the mean D/C ratios between the two studies are different, further efforts may be employed to ensure that such a difference is in fact statistically significant. A larger sample with more diverse representatives from various races may be used in this endeavor.

\section{References}

1. Cala LA, Thickbroom GW, Black JL, Collins DW, Mastaglia FL. Brain density and cerebrospinal fluid space size: $\mathrm{CT}$ of normal volunteers. Am J Neuroradiol. 1981; 2(1):41-7.

2. Forbes G, Gehring DG, Gorman CA, Brennan MD, Jackson IT. Volume measurements of normal orbital structures by computed tomographic analysis. Am J Roentgenol. 1985; 145(1):149-54.

3. Galvez M, York II GE, Eastwood JD. CT perfusion parameter values in regions of diffusion abnormalities. Am J Neuroradiol. 2004; 25(7):120510.

4. Rojas CA, Vermess D, Bertozzi JC, Whitlow J, Guidi C, Martinez CR. Normal thickness and appearance of the prevertebral soft tissues on multidetector CT. Am J Neuroradiol. 2009; 30(1):136-41.

5. Lee JS, Lim DW, Lee SH, Oum BS, Kim HJ, Lee HJ. Normative measurements of Korean orbital structures revealed by computerized tomography. Acta Ophthalmol Scand. 2001; 79(2):197-200.

6. Kim IT, Choi JB. Normal range of exophthalmos values on orbit computerized tomography in Koreans. Ophthalmologica. 2001; 215(3):156-62.

7. Özgen A, Aydingoz U. Normative measurements of orbital structures using MRI. J Comput Assist Tomogr. 2000; 24(3):493-6.

8. Hopper KD, Sherman JL, Boal DK, Eggli KD. CT and MR imaging of the pediatric orbit. RadioGraphics. 1992; 12(3):485-503.

\section{Appendix A}

Computation of Sample Size:

As computed at http://www.quantitativeskills.com/sisa/ calculations/samsize.htm

For the computation of the sample size, the expected values from the journal were taken from the mean and standard deviation of the $\mathrm{D} / \mathrm{C}$ ratio which was the suggested index of the study.

\begin{tabular}{|l|l|}
\hline Expected Average1 & 0.28766868 (from the present study) \\
\hline Expected Average 2 & 0.31 (from the journal) \\
\hline Std Dev 1 ; Tolerance & 0.035938041 (from the present study) \\
\hline Std Dev 2 & 0.03 (from the journal) \\
\hline Alloc Ratio & 1.00 \\
\hline Continuity Correction & Yes (for averages) \\
\hline
\end{tabular}

RESULTS for double sided

\begin{tabular}{lcccc} 
alpha & \multicolumn{5}{c}{ power } \\
& 0.6 & 0.7 & $\underline{0.8}$ & 0.9 \\
\hline 0.1 & 17 & 22 & 28 & 39 \\
0.05 & 23 & 28 & 36 & 47 \\
$\underline{0.01}$ & 37 & 44 & $\underline{\mathbf{5 3}}$ & 67 \\
0.001 & 58 & 67 & $\mathbf{7 8}$ & 94
\end{tabular}

\section{RESULTS for single sided}

\begin{tabular}{lcccc} 
alpha & \multicolumn{5}{c}{ power } \\
& 0.6 & 0.7 & 0.8 & 0.9 \\
\hline 0.1 & 11 & 15 & 21 & 30 \\
0.05 & 17 & 22 & 28 & 39 \\
0.01 & 31 & 37 & 46 & 59 \\
0.001 & 52 & 60 & 70 & 86 \\
Optimum allocation ratio equals: 1.02
\end{tabular}


Appendix B
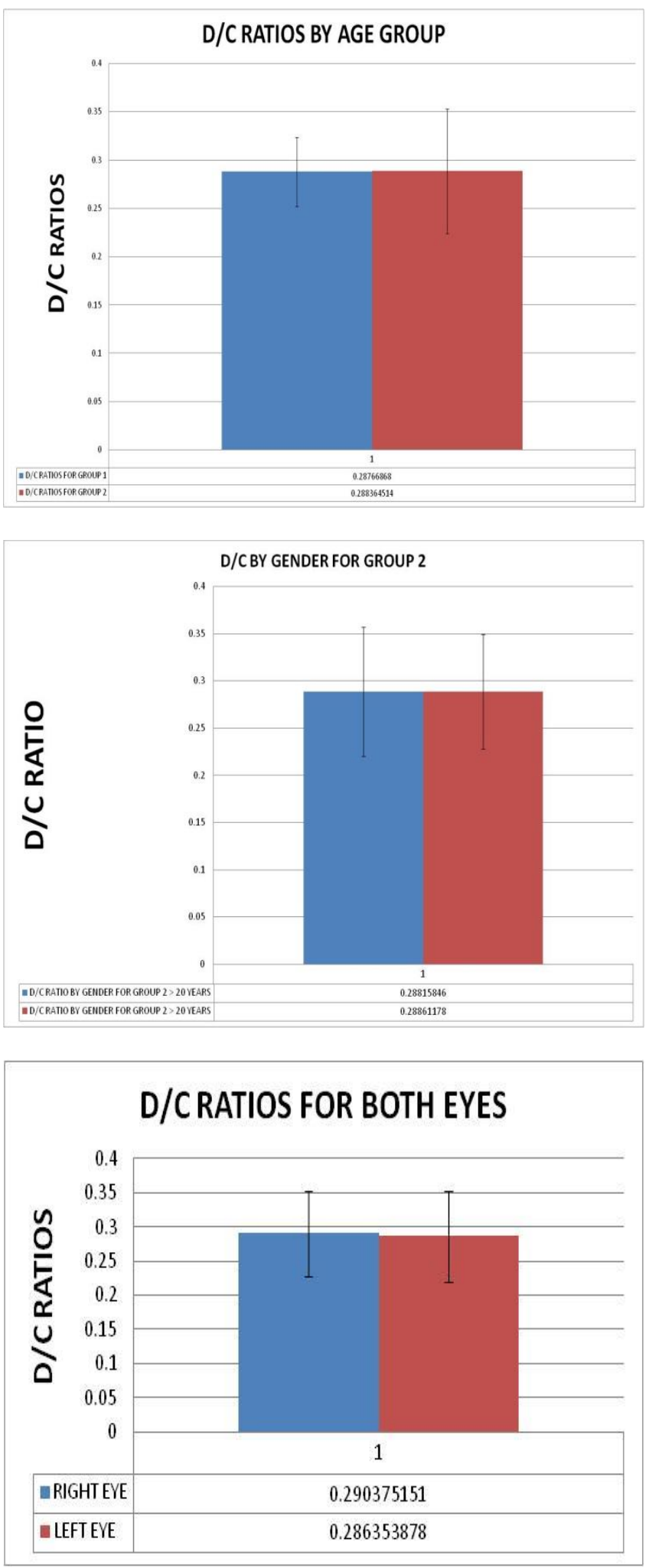

Statistical considerations: Some of the measurements when checked did not have a normal distribution. The pvalues where therefore counterchecked using MannWhitney nonparametric test. The test accepts null hypothesis of equality of means with p-value 0.0566 (but rejects equality at level 0.10). The conclusion was otherwise the same as with the T-test. 